\title{
Genotypic Variation in Responses of Citrus spp. to Arbuscular Mycorrhizal Fungi
}

\author{
Somchit Youpensuk (Corresponding author) \\ Department of Biology, Faculty of Science, Chiang Mai University \\ Chiang Mai 50200, Thailand \\ Tel: 66-053-941-946-8 ext. $143 \quad$ E-mail: scboi027@chiangmai.ac.th
}

\begin{abstract}
Sittichai Lordkaew
Multiple Cropping Centre, Faculty of Agriculture, Chiang Mai University,

Chiang Mai 50200, Thailand
\end{abstract}

Tel: 66-081-796-0449 E-mail: s.lord@chiangmai.ac.th

Benjavan Rerkasem

Department of Agronomy, Faculty of Agriculture, Chiang Mai University,

Chiang Mai 50200, Thailand

Tel: 66-086-182-4678Ｅ-mail: benjavan@chiangmai.ac.th

The research is financed by the Thailand Research Fund and Commission on Higher Education

\begin{abstract}
Thailand is part of Southeast Asia that covers the center of diversity of citrus species, where various species of the genus are widely grown. One of the most common is tangerine (Citrus reticulata), which is commonly grown by grafting on rootstocks of different tangerine varieties or other citrus species. The objective of this study is to investigate responses of some Citrus spp. seedlings to arbuscular mycorrhizal (AM) fungi, and thus their potential as rootstocks. The experiment was done with four tangerine varieties, Cleopatra, Fremont, Ocean and Sainamphung; and four other citrus species, lime (C. aurantifolia), pomelo (C. maxima), sweet orange (C. sinensis) and Troyer citrange (Citrus sinensis $\times$ Poncirus trifoliata), in pots for five months. Roots of non-inoculated plants were not infected with AM fungi, while inoculated plants were heavily infected with AM fungi, and contained 14-28 AM spores per $10 \mathrm{~g}$ of rhizosphere soil. Most of the citrus responded positively to AM fungi, but with different magnitudes among the varieties and species. Lime and pomelo seedlings were fast growing compared to other citrus species. Total dry weight and $\mathrm{N}, \mathrm{P}, \mathrm{K}$ and $\mathrm{Mg}$ contents were increased most strongly by AM fungi in lime, pomelo and tangerine varieties Ocean, Fremont and Sainamphung, but little or none in Cleopatra, Troyer and sweet orange. Lime was the most outstanding in the response to AM fungi, followed by Ocean tangerine and pomelo. The potential of lime, pomelo and Ocean tangerine as rootstock for tangerine should be further investigated.
\end{abstract}

Keywords: Arbuscular mycorrhizal fungi, Citrus spp., Response

\section{Introduction}

Southeast Asia is generally considered the center of diversity of citrus (Moore, 2001). Various kinds of citrus plants are grown in all regions of Thailand, one of the most widely grown is tangerine (C. reticulata) especially the variety Sainamphung. Tangerine is commonly grown by grafting on rootstocks of different tangerine varieties or other citrus species. Tangerine variety Cleopatra and a hybrid citrange or Troyer (Citrus sinensis $\times$ Poncirus trifoliata) are used widely as rootstock in Sainamphung tangerine orchards in Thailand. Arbuscular mycorrhizal (AM) fungi are mutualistic associations with plant roots. They improve the nutritional status of plants resulting in increased growth of the host plants, and they can also improve soil structure (Douds and Millner, 999). AM fungi are an important part of sustainable agricultural systems. Youpensuk et al. (2008) reported that twenty-two species of AM fungi were found in tangerine 
orchards of Chiang Mai province and they increased growth of air layered tangerine variety Sainamphung especially in pots applied only $\mathrm{N}$ without $\mathrm{P}$ fertilizer. The objective of this study is to investigate responses to AM fungi of seedlings of tangerine varieties and other common citrus species, and thus their potential as rootstocks.

\section{Materials and Methods}

\subsection{Preparing citrus seedlings}

Tangerine (C. reticulata) varieties examined in this experiment were Cleopatra, Fremont, Ocean and Sainamphung, and the other common citrus plants were lime (C. aurantifolia), pomelo (C. maxima), sweet orange (C. sinensis) and a hybrid citrange or Troyer (Citrus sinensis $\times$ Poncirus trifoliata). The plants were grown from seeds that had outer seed coats were peeled off before germination in sterile soil in plastic trays and watered twice a day.

\subsection{The responses of Citrus spp. seedlings to AM fungi}

One month old seedlings were transplanted into drainable plastic pots containing $6 \mathrm{~kg}$ sterile soil, with one seedling per pot. The soil was a sandy clay loam with $\mathrm{pH}$ of 6.0 . The soil contained $0.90 \mathrm{~g} / \mathrm{kg}$ total N, $4.1 \mathrm{mg} / \mathrm{kg}$ available P, 53.0 $\mathrm{mg} / \mathrm{kg}$ extractable $\mathrm{K}$, and $18.5 \mathrm{~g} / \mathrm{kg}$ organic matter. Spores of mixed AM fungal species were collected from the rhizosphere of Citrus spp. in northern Thailand. For inoculated treatments, three hundred spores of mixed species of AM fungi were inoculated to the planting hole in each pot. All treatments had four replications. Seedlings were watered once a day. Five months after transplanting, shoot height was measured for each plant. Shoots were separated from roots at the soil surface and dried at $70^{\circ} \mathrm{C}$ for three days to evaluate for shoot dry weight. Soil in each pot was divided into two subsamples. Roots were washed from each one soil subsample and dried at $70^{\circ} \mathrm{C}$ for three days to evaluate for root dry weight. After drying, shoot and root samples were ground and analyzed for $\mathrm{N}$ contents in citrus plants by Kjedahl method. Dry ashes of the samples of citrus plants were evaluated for P by molypdovanado-phosphoric acid method, and evaluated for $\mathrm{K}$ and $\mathrm{Mg}$ by atomic absorption spectrophotometer.

\subsection{Assessment of root colonization and spore density of AM fungi}

Soil and root samples from the second subsamples of each pot were used for assessment of root colonization and spore density of AM fungi. Fifty g of soil sample from each pot was used to assess spore density and identification of the AM fungi. The soil samples were wet sieved through $750,250,100$, and $53 \mu \mathrm{m}$ mesh sieves. The sieved soil on each 250 , 100 , and $53 \mu \mathrm{m}$ mesh was centrifuged at $2000 \mathrm{rpm}$ for $5 \mathrm{~min}$ and floating particles removed. The soil was suspended in $50 \%$ sucrose and centrifuged one min at $2000 \mathrm{rpm}$. After centrifugation, spores in the supernatant were poured over the finest sieve and washed with water to remove the sucrose before vacuum filtration on filter paper with gridlines. Spores on filter paper were kept in Petri dishes and counted under a stereomicroscope. The spores of AM fungi were identified according to morphological characteristics of AM fungal descriptions (Schenck and Perez, 1988; INVAM website, 2008).

Root samples were washed with tap water and cut into about $1 \mathrm{~cm}$ in length, cleared in $10 \% \mathrm{KOH}$ at $121^{\circ} \mathrm{C}$ for $15 \mathrm{~min}$, washed over a sieve with tap water, and stained with $0.05 \%$ trypan blue in lactoglycerol at $121^{\circ} \mathrm{C}$ for $15 \mathrm{~min}$. The stained root segments were randomly picked with fine tip forceps and mounted on slides. Thirty pieces of root segments from each sample were assessed root colonization of AM fungi according to the method of McGonigle et al (1990) under compound microscope.

\subsection{Statistical analysis}

The data were analyzed with SPSS software program for analysis of variance (ANOVA). Duncan's Multiple Range Test at $P \leq 0.05$ was used to determine significances of treatment means.

\section{Results and Discussion}

Roots of non-inoculated plants were not infected with AM fungi. Percentage of root colonization of AM fungi in roots of inoculated citrus plants was very high from $75-96 \%$ (Table 1). Spore densities in the pots were about 14-28 spores per $10 \mathrm{~g}$ soil. Spores production may not correlate to percentage of root colonization it depends on AM fungal ability to produce spores in each soil condition (Smith and Read, 1997; Youpensuk et al., 2006). Twenty species of AM fungi were found in pots of inoculated citrus plants after five months of inoculation (Table 2). They were in three genera of Acaulospora (7 species), Glomus (12 species) and Scutellospora (1 species). The most AM species frequently found in all pots of inoculated citrus plants were Acaulospora scrobiculata, Glomus etunicatum and G. mosseae. This was similar to the report of Youpensuk et al. (2008) which found that G. etunicatum and A. scrobiculata were the most frequently found in tangerine orchards in Chiang Mai province. In this experiment, some 13-14 species of AM fungi were found in the rhizosphere of tangerine. There were some difference in the AM fungal species among the different varieties of tangerine, such as G. aggregatum was found only in the tangerine variety Cleopatra but A. rugosa was not found in this variety while it was found in the other varieties, and $A$. delicata was found in only tangerine variety Ocean. There were 2-3 more AM fungal species in the rhizosphere of the other citrus species. The most abundant in AM fungal species was in the hybrid citrange or Troyer (Table 2). Bever (2002) reported that although AM fungal species can associate with all host but they have host-specific differences in their sporulation growth rates. Although they were not very different in 
number of AM fungal species and percentage of root colonization but significant variation in responses to AM fungi were found between the tangerine varieties and among the citrus species (Table 3). Inoculation by AM fungi generally increased plant height in the citrus, but most strongly in pomelo, lime and Ocean tangerine. Inoculation with AM fungi increased shoot dry weight most strongly, by doubling the shoot dry weight or more, in two tangerine varieties, Fremont and Ocean, and also in lime and pomelo, less effect on the tangerine varieties Cleopatra and Sainamphung, but had little effect on sweet orange and Troyer. Root dry weight of AM inoculated lime was three times that in non-inoculated. AM inoculation did not have significant effect on root dry weight of any of the tangerine and other citrus species. Root to shoot ratios of inoculated treatments of all tangerine varieties and pomelo tended to be lower than those of non-inoculated treatments. This may be the result of greater nutrient uptake efficiency by the external hyphae of mycorrhizal roots, which resulted in increased shoot growth of the host plant. Mycorrhizal plants are frequently found to have lower root to shoot ratios than non-mycorrhizal plants (Marschner et al., 1996; Youpensuk et al., 2005). Lime was an exception, as both its root growth was tripled by AM inoculation while the shoot growth was only doubled, which resulted in the root to shoot ratio being increased by AM inoculation.

Comparative responses to AM fungi in these citrus species and tangerine varieties can be seen more clearly by comparing plant total dry weight with and without mycorrhiza (Table 4). Lime responded most strongly to AM fungi with a $115.5 \%$ increase in total dry weight, followed closely by tangerine Ocean with $97.7 \%$ and pomelo with $91.4 \%$ increase in dry weight. Significant, although lower, responses to AM fungi were found in tangerine Fremont (78.4\%) and Sainamphung (64.9\%). The response to AM fungi was not significant in Cleopatra tangerine, sweet orange and Troyer. The low response to AM fungi in Troyer has been previously reported by Camprubi and Calvet (1996). These authors, however, also reported that rootstocks of sour orange and Cleopatra were more mycorrhizal dependent than Troyer and Swingle citrumelo (C. paradise $\times P$. trifoliata). The lack of response to AM fungi in sweet orange agrees with the report of Jifon et al. (2002), who reported that sweet orange did not respond to Glomus intraradices while sour orange or C. aurantium had about $15 \%$ of mycorrhizal dependence in high level of $\mathrm{P}$ and $70 \mathrm{~Pa}$ of $\mathrm{CO}_{2}$. The results indicated that varieties or species of plants can respond differently to AM fungi. Soil condition also affect to responses of plants to AM fungi such as levels of available P in soil that AM plants more response to AM fungi in low P soil than in high P soil (Graham et al., 1997). In addition to variation in the effect of AM fungi on plant dry weight among the citrus species and tangerine varieties, AM fungi also had different effects on nutrients uptake of the different citrus plants that were sometimes similar to and sometimes different from the effects on dry weight (Table 5). Although AM fungi had little effect on dry weight of Cleopatra tangerine, but it significantly increased N, P and K content of the host plant. Similarly AM fungi significantly increased P content of sweet orange and N and P content of Troyer even though it did not affect their dry weight. The effect of AM fungi on nutrient uptake in some of the more responsive varieties of tangerine and species of citrus was very large. For example, P content of Fremont tangerine, lime and pomelo was increased by more than $300 \%$ by AM fungi. The largest increases in the uptake of these nutrients by AM fungi were found in Fremont tangerine, lime and pomelo, while the effect on Troyer was small and on Sweet orange nil. Troyer and Cleopatra are tolerlant to Phytophthora spp. that cause root rot of plants (Graham and Timmer, 2009). Therefore, they are widely used in Thailand as rootstock for Sainamphung, but their limited response to AM fungi is a cause for concern. Should this response continue into trees in the orchards, it would mean that benefits from AM fungi will be minimal in commercial tangerine orchards. Many experiments reported that AM fungi increased P contents of the host plants. But AM fungi may or may not increase uptake of these $\mathrm{N}, \mathrm{K}$ and $\mathrm{Mg}$, depending on host plants, species of AM fungi and soil conditions (Marschner and Dell, 1994; Taylor and Harrier, 2001; Rutto et al., 2002). Wu and Xia (2006) reported that level of $\mathrm{Mg}$ in leaves of tangerine inoculated with AM fungi was higher in AM seedlings than those in non-AM seedlings under well-watered and water stress conditions. While the levels of $\mathrm{K}$ and $\mathrm{Ca}$ in leaves and roots were significantly higher in AM seedlings than those in non-AM seedlings only under well-water conditions.

\section{Conclusions}

All of the tangerine varieties and other citrus species studied were well colonized by AM fungi. Judging by spore morphology a whole range of AM fungi was found in the rhizosphere of these citruses. All of citrus also benefited from association with the AM fungi, but with different magnitudes in different varieties and species. Lime was the most outstanding in the response to AM fungi, followed by Ocean tangerine and pomelo. The limited response to AM fungi in Troyer and Cleopatra tangerine that are used as rootstocks in commercial tangerine orchards suggests a re-evaluation of tangerine rootstocks may be worthwhile. On the other hand the potential of lime, pomelo and Ocean tangerine as rootstock for tangerine should be further investigated.

\section{References}

Bever, J.D. (2002). Host-specificity of AM fungal population growth rates can generate feedback on plant growth. Plant and Soil, 224, 281-290.

Camprubi, A., \& Calvet, C. (1996). Isolation and screening of mycorrhizal fungi from citrus nurseries and orchards and inoculation studies. HortScience, 31, 366-369. 
Douds, D.D., \& Millner, P.D. (1999). Biodiversity of arbuscular mycorrhizal fungi in agroecosystems. Agriculture, Ecosystems \& Environment, 74, 119-142.

Graham, J.H., Duncan, L.W., \& Eissenstat, D.M. (1997). Carbohydrate allocation patterns in citrus genotypes as affected by phosphorus nutrition, mycorrhizal colonization and mycorrhizal dependency. New Phytology, 135, 335-343.

Graham, J.H., \& Timmer, L.W. (2009). Phytophthora Diseases of Citrus. University of Florida IFAS Extension. [Online] Available: http://edis.ifas.ufl.edu/CH087 (January 20, 2009).

INVAM website. (2008). Species descriptions from reference cultures. [Online] Available: http://invam.caf.wvu.edu/fungi/taxonomy/speciesID.htm (August 3, 2008).

Jifon, J.L., Graham, J.H., Drouillard, D.L., \& Syvertsen, P. (2002). Growth depression of mycorrhizal Citrus seedlings grown at high phosphorus supply is mitigated by elevated $\mathrm{CO}_{2}$. New Phytology, 153, 133-142.

Marschner, H., \& Dell, B. (1994). Nutrient uptake in mycorrhizal symbiosis. Plant and Soil, 159, 89-102.

Marschner, H., Kirby, E., \& Cakmak, I. (1996). Effect of mineral nutritional status on shoot-root partitioning of photoassimilates and cycling of mineral nutrients. Journal of Experimental Botany, 47, 1255-1263.

McGonigle, T.P., Miller, M.H., Evans, D.G., Fairchild, G.L., \& Swan, J.A. (1990). A new method which gives an objective measure of colonization of roots by vesicular-arbuscular mycorrhizal fungi. New Phytololy, 115, 495-501.

Moore, G.A. (2001). Oranges and lemons: clues to the taxonomy of Citrus from molecular markers. Trends in Genetics, $17,536-540$.

Rutto, K.L., Mizutani, F., \& Kadoya, K. (2002). Effect of root-zone flooding on mycorrhizal and non-mycorrhizal peach (Prunus persica Batsch) seedlings. Scientia Horticulturae, 94, 285-295.

Schenck, N.C., \& Perez, Y. (1988). Manual for the Identification of VA Mycorrhizal Fungi (2nd ed.) Florida: UNVAM Gainesville.

Smith, S.E., \& Read, D.J. (1997). Mycorrhizal Symbiosis (2nd ed.), London: Academic Press.

Taylor, J., \& Harrier, L.A. (2001). A comparison of development and mineral nutrition of micropropagated Fragaria $\mathrm{x}$ ananassa cv. Elvira (strawberry) when colonised by nine species of arbuscular mycorrhizal fungi. Applied Soil Ecology, $18,205-215$.

Wu, Q.S., \& Xia, R.X. (2006). Arbuscular mycorrhizal fungi influence growth, osmotic adjustment and photosynthesis of citrus under well-watered and water stress conditions. Journal of Plant Physiology, 163, 417-425.

Youpensuk, S., Rerkasem, B., Dell, B. \& Lumyong, S. (2005). Effects of arbuscular mycorrhizal fungi on a fallow enriching tree (Macaranga denticulata). Fungal Diversity, 18, 189-199.

Youpensuk, S., Lordkaew, S., \& Rerkasem, B. (2006). Comparing the effect of arbuscular mycorrhizal fungi on upland rice and Macaranga denticulata in soil with different level of acidity. ScienceAsia, 32, 121-126.

Youpensuk, S., Lordkaew, S. Rerkasem, B. (2008). Arbuscular mycorrhizal fungi associated with tangerine (Citrus reticulata) in Chiang Mai province, northern Thailand, and their effects on the host plant. ScienceAsia, 34, 259-264.

Table 1. Means of root colonization and spore densities of arbuscular mycorrhizal fungi in pots of inoculated citrus plants

\begin{tabular}{lll}
\hline Species or variety of citrus plant & Mean of root colonization (\%) & $\begin{array}{c}\text { Spore density } \\
\text { (spores/10 g soil) }\end{array}$ \\
\hline Cleopatra & $75.0 \mathrm{~b}$ & $28 \mathrm{a}$ \\
Fremont & $95.5 \mathrm{a}$ & $14 \mathrm{~d}$ \\
Ocean & $90.6 \mathrm{a}$ & $16 \mathrm{bcd}$ \\
Sainamphung & $90.6 \mathrm{a}$ & $23 \mathrm{ab}$ \\
Lime & $91.8 \mathrm{a}$ & $21 \mathrm{abc}$ \\
Pomelo & $96.0 \mathrm{a}$ & $22 \mathrm{abc}$ \\
Sweet Orange & $95.1 \mathrm{a}$ & $21 \mathrm{abc}$ \\
Troyer & $94.5 \mathrm{a}$ & $15 \mathrm{~cd}$ \\
\hline
\end{tabular}

Means in the same column followed by different letters are significantly different $(P \leq 0.05)$. 


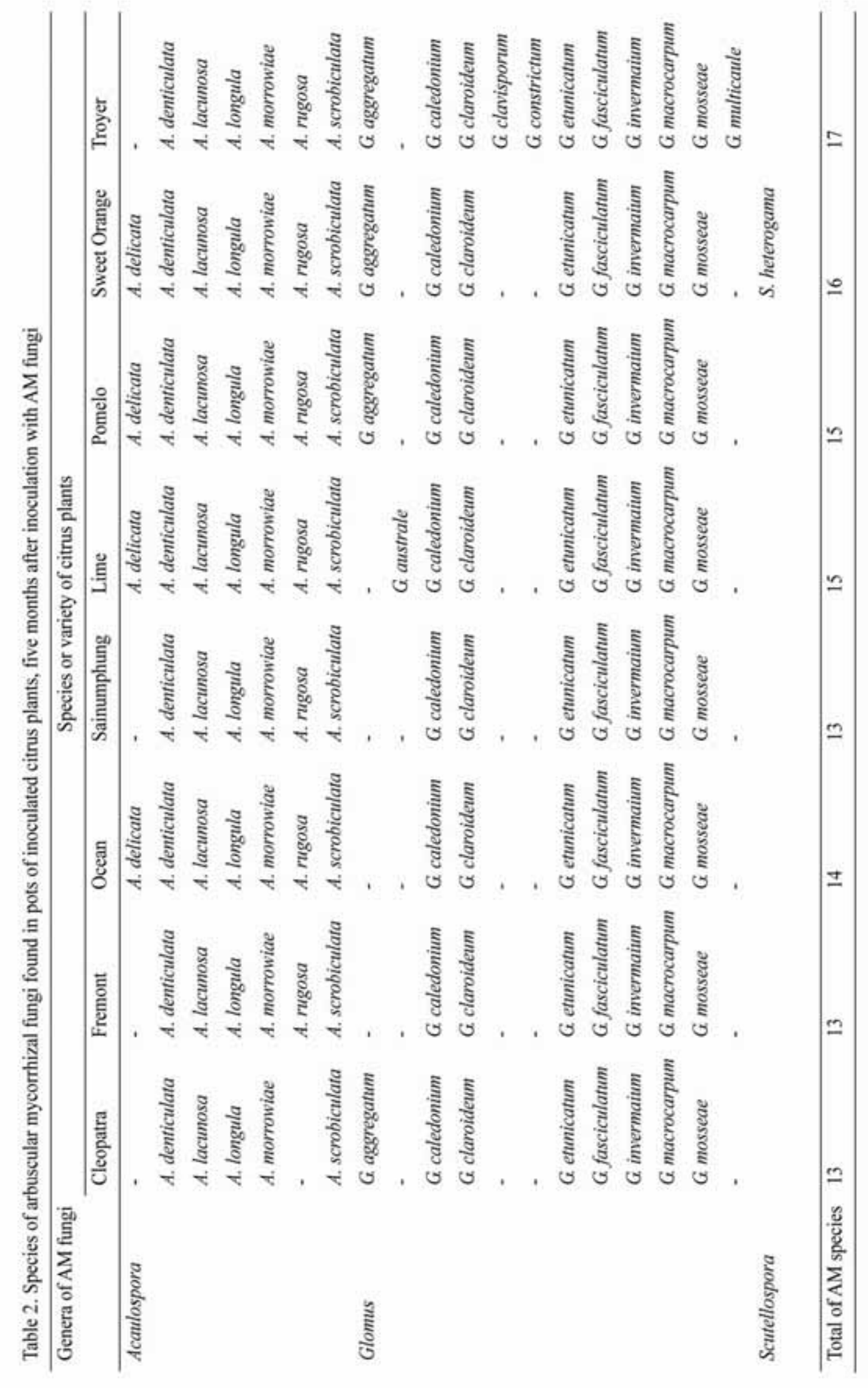


Table 3. Effect of AM fungi on height, shoot and root dry weight (DW) of tangerine varieties and other citrus plants, five months after inoculation

\begin{tabular}{|c|c|c|c|c|}
\hline $\begin{array}{l}\text { Species or variety of } \\
\text { citrus plant }\end{array}$ & $\begin{array}{l}\text { Height } \\
(\mathrm{cm})\end{array}$ & $\begin{array}{l}\text { Shoot DW } \\
\text { (g/plant) }\end{array}$ & $\begin{array}{l}\text { Root DW } \\
\text { (g/plant) }\end{array}$ & Root:shoot \\
\hline Cleopatra (M-) & $23.67 \mathrm{f}$ & $1.79 \mathrm{e}$ & $1.47 \mathrm{~d}$ & 0.82 \\
\hline Cleopatra $(\mathrm{M}+)$ & $32.73 \mathrm{de}$ & $2.73 \mathrm{de}$ & $1.32 \mathrm{~d}$ & 0.48 \\
\hline Fremont (M-) & $29.23 \mathrm{ef}$ & $2.34 \mathrm{de}$ & $2.06 \mathrm{~cd}$ & 0.88 \\
\hline Fremont $(\mathrm{M}+)$ & $37.78 \mathrm{~cd}$ & $4.76 b c$ & $3.09 \mathrm{~cd}$ & 0.65 \\
\hline Ocean (M-) & $29.98 \mathrm{e}$ & $2.63 \mathrm{de}$ & $1.69 \mathrm{~cd}$ & 0.64 \\
\hline Ocean $(\mathrm{M}+)$ & $46.60 \mathrm{bc}$ & $6.14 b c$ & $2.38 \mathrm{~cd}$ & 0.39 \\
\hline Sainamphung (M-) & 32.90de & $1.84 \mathrm{e}$ & $1.98 \mathrm{~cd}$ & 1.08 \\
\hline Sainamphung $(\mathrm{M}+)$ & $33.10 \mathrm{de}$ & $3.35 \mathrm{de}$ & $2.95 \mathrm{~cd}$ & 0.88 \\
\hline Lime (M-) & $48.80 \mathrm{bc}$ & $5.02 \mathrm{bc}$ & $2.45 b$ & 0.49 \\
\hline Lime $(\mathrm{M}+)$ & $65.93 a$ & $11.79 \mathrm{a}$ & $7.31 \mathrm{bc}$ & 0.62 \\
\hline Pomelo (M-) & $39.35 b c$ & $4.97 b$ & $3.87 \mathrm{ab}$ & 0.78 \\
\hline Pomelo (M+) & $62.55 \mathrm{a}$ & $11.08 \mathrm{a}$ & $5.84 a$ & 0.53 \\
\hline Sweet orange (M-) & $33.85 \mathrm{~cd}$ & $5.44 b$ & $3.61 \mathrm{ab}$ & 0.66 \\
\hline Sweet orange $(\mathrm{M}+)$ & $44.38 b c$ & $5.53 b$ & $3.68 \mathrm{ab}$ & 0.67 \\
\hline Troyer (M-) & $51.00 \mathrm{bc}$ & $3.80 \mathrm{~cd}$ & $2.40 \mathrm{~cd}$ & 0.63 \\
\hline Troyer $(\mathrm{M}+)$ & $55.13 b$ & $3.87 \mathrm{~cd}$ & $2.40 \mathrm{~cd}$ & 0.62 \\
\hline \multicolumn{5}{|l|}{ Analysis of variance } \\
\hline Citrus & $* * *$ & $* * *$ & $* * *$ & \\
\hline Inoculation & $* * *$ & $* * *$ & NS & \\
\hline Citrus $\times$ Inoculation & NS & $* * *$ & NS & \\
\hline
\end{tabular}

M-, non-inoculated with AM fungi; M+, inoculated with AM fungi. Means in the same column followed by different letters are significantly different $(P \leq 0.05)$. ${ }^{* *}$, significant at $P \leq 0.001$; NS, not significant. 
Table 4. Total dry weight and response to mycorrhizal fungi of tangerine varieties and other citrus plants, five months after inoculation with arbuscular mycorrhizal fungi

\begin{tabular}{|c|c|c|c|}
\hline \multirow{2}{*}{ Plant } & \multicolumn{2}{|c|}{ Total dry weight (g/plant) } & \multirow{2}{*}{$\begin{array}{l}\text { Response to } \\
\text { mycorrhizal }^{*}(\%)\end{array}$} \\
\hline & Non-mycorrhizal plant & Mycorrhizal plant & \\
\hline \multicolumn{4}{|l|}{ Tangerine } \\
\hline Cleopatra & $3.26 \mathrm{cA}$ & $4.04 \mathrm{cA}$ & 23.9 \\
\hline Fremont & $4.40 \mathrm{cB}$ & $7.85 \mathrm{bcA}$ & 78.4 \\
\hline Ocean & $4.31 \mathrm{cB}$ & $8.52 \mathrm{bcA}$ & 97.7 \\
\hline Sainamphung & $3.82 \mathrm{cB}$ & $6.30 \mathrm{cA}$ & 64.9 \\
\hline \multicolumn{4}{|c|}{ Other citrus spp. } \\
\hline Lime & $7.47 \mathrm{abB}$ & $16.10 \mathrm{aA}$ & 115.5 \\
\hline Pomelo & $8.84 \mathrm{aB}$ & $16.92 \mathrm{aA}$ & 91.4 \\
\hline Sweet Orange & $9.05 \mathrm{aA}$ & $9.16 \mathrm{bA}$ & 1.2 \\
\hline Troyer & $6.20 \mathrm{bcA}$ & $6.27 \mathrm{cA}$ & 1.1 \\
\hline
\end{tabular}

*Dry weight of mycorrhizal plant as percentage of dry weight of non-mycorrhizal plant. Means of total dry weight followed by different letters (lower case in the same column and capital letter in the same row) were significantly different $(P \leq 0.05)$.

Table 5. Effect of arbuscular mycorrhizal fungi on nutrient contents in tangerine varieties and other citrus plants, five months after inoculation.

\begin{tabular}{|c|c|c|c|c|}
\hline \multirow{2}{*}{$\begin{array}{l}\text { Species or variety } \\
\text { of citrus plant }\end{array}$} & \multicolumn{4}{|c|}{ Nutrient content in citrus plants (mg/plant) } \\
\hline & $\mathrm{N}$ & $\mathrm{P}$ & $\mathrm{K}$ & $\mathrm{Mg}$ \\
\hline Cleopatra (M-) & $47.63 b$ & $5.98 b$ & $47.25 b$ & $8.09 \mathrm{a}$ \\
\hline Cleopatra $(\mathrm{M}+)$ & $70.85 a$ & $12.99 \mathrm{a}$ & $58.67 \mathrm{a}$ & $10.93 \mathrm{a}$ \\
\hline Fremont (M-) & $59.01 b$ & $8.33 b$ & $109.84 b$ & $9.22 b$ \\
\hline Fremont $(\mathrm{M}+)$ & $139.00 \mathrm{a}$ & $38.19 \mathrm{a}$ & $153.39 \mathrm{a}$ & $14.25 \mathrm{a}$ \\
\hline Ocean (M-) & $67.41 b$ & $8.79 b$ & $104.31 b$ & $8.56 b$ \\
\hline Ocean $(\mathrm{M}+)$ & $134.08 \mathrm{a}$ & $24.22 \mathrm{a}$ & $142.00 \mathrm{a}$ & $13.49 \mathrm{a}$ \\
\hline Sainamphung (M-) & $47.51 b$ & $10.12 b$ & $86.54 b$ & $9.72 b$ \\
\hline Sainamphung $(\mathrm{M}+)$ & $111.46 \mathrm{a}$ & $30.11 \mathrm{a}$ & $124.26 \mathrm{a}$ & $15.47 \mathrm{a}$ \\
\hline Lime (M-) & $104.44 b$ & $14.46 b$ & $154.56 b$ & $14.90 \mathrm{~b}$ \\
\hline Lime $(\mathrm{M}+)$ & $239.31 \mathrm{a}$ & $62.51 \mathrm{a}$ & $312.07 \mathrm{a}$ & $37.32 \mathrm{a}$ \\
\hline Pomelo (M-) & $95.91 b$ & $10.89 b$ & $149.80 \mathrm{~b}$ & $20.00 \mathrm{~b}$ \\
\hline Pomelo (M+) & $201.97 \mathrm{a}$ & $44.52 \mathrm{a}$ & $270.66 \mathrm{a}$ & $34.02 \mathrm{a}$ \\
\hline Sweet Orange (M-) & $141.12 \mathrm{a}$ & $18.45 b$ & $220.37 \mathrm{a}$ & $17.92 \mathrm{a}$ \\
\hline Sweet Orange $(\mathrm{M}+)$ & $151.03 \mathrm{a}$ & $28.73 a$ & $161.70 \mathrm{~b}$ & $14.92 \mathrm{a}$ \\
\hline Troyer (M-) & $71.72 b$ & $15.66 b$ & $114.22 \mathrm{a}$ & $12.56 \mathrm{a}$ \\
\hline Troyer $(\mathrm{M}+)$ & $107.05 \mathrm{a}$ & $27.28 \mathrm{a}$ & $114.16 \mathrm{a}$ & $12.19 \mathrm{a}$ \\
\hline
\end{tabular}

Means of non-inoculated (M-) and inoculated (M+) with AM fungi in the same tangerine variety or citrus species followed by different letters were significantly different $(P \leq 0.05)$. 